
SUSTAINABILITY

\author{
Anthony Marchese, Rowan University \\ Beena Sukumaran, Rowan University \\ Catherine Yang, Rowan University \\ Courtney Richmond, Rowan University \\ Demond Miller, Rowan University \\ Joseph Orlins, Rowan University \\ Kauser Jahan, Rowan University \\ Mariano Savelski, Rowan University \\ Paris von Lockette, Rowan University \\ Patricia Mosto, Rowan University \\ Stephanie Farrell, Rowan University \\ William Riddell, Rowan University \\ Ying Tang, Rowan University \\ Yusuf Mehta, Rowan University
}


DELOS 1526

NSF GRANTEES POSTER SESSION

\title{
Research Experiences in Pollution Prevention and Sustainability
}

\begin{abstract}
Rowan University hosts an NSF REU Site in Pollution Prevention and Sustainability every summer. Undergraduate students from various science and engineering disciplines from all over the USA participated in these pollution prevention research activities. Engineering faculty mentored students for an eight-week period. While research was the primary activity, other community building modules, seminars, social events and communication strengthening exercises were an integral part of the Pollution Prevention experience. A special workshop on environmental ethics and environmental justice was also offered to help students connect pollution prevention issues to environmental ethics. The program was highly successful as evident by resulting publications, student awards and $\%$ of students pursuing graduate school. The theme seems to appeal to a wide audience of engineering and science students.
\end{abstract}

